\title{
Microcephalic primordial dwarfism, Dauber type
}

INSERM

\section{Source}

INSERM. (1999). Orphanet: an online rare disease and orphan drug data base.

Microcephalic primordial dwarfism, Dauber type. ORPHA:319675

Microcephalic primordial dwarfism, Dauber type is a rare, genetic developmental defect during embryogenesis characterized by severe pre- and postnatal growth retardation, severe microcephaly, severe developmental delay and intelletual disability, severe adult short stature and facial dysmorphism (incl. hypotelorism, small ears, prominent nose). Other reported features include skeletal anomalies (Madelung deformity, clinodactyly, mild lumbar scoliosis, bilateral hip dysplasia) and seizures. Absence of thelarche and menarche is also associated. 